\title{
Utilizing Mindfulness as an Evening Reflection at Residential Camp ${ }^{1}$
}

Heather Janney ${ }^{2}$

\section{Overall Introduction}

Mindfulness is paying attention to what is going on around us in a way that allows us to respond rather than react (Naik, Harris, \& Forthun, 2013). In addition, it is a quality of being still on the inside and recognizing that this ability is always available, even when our life or circumstances feel out of our control and chaotic. Individuals come into many instances in their lives where they are not used to simply stopping and paying attention to things around them. If we start training youth to try this practice, it can assist in self-insight and awareness, increased compassion and empathy, reduced stress and anxiety, and increased control over automatic behaviors (Davis \& Hayes, 2011).

Utilizing mindfulness as an evening reflection at residential camps has been developed as a tool for use at the end of the day during residential camps, but language may be modified for use at the end of classes or day camps. It is recommended to do only one lesson per day. Each lesson should last 15-20 minutes. These lessons are developed as a way for youth to reflect on their activities throughout the day.

\section{Supplies}

A bell is used throughout these lessons as an "anchor," or way to draw and keep youth's attention. These may be purchased at in-person or online retailers. The bell should be lower pitched and soothing in sound. Please keep in mind that youth with emotional disabilities could react poorly to unexpected sounds. To help with this, be sure to let youth know what you plan to do and explain the use of the bell. Ring it prior to use in the activity so that they feel comfortable with the sound and to help avoid any poor reactions to unexpected sounds.

The only other materials needed are the lesson scripts or dialogues included below. Please note that within the dialogues, the italicized sentences and phrases are intended for direction and your information.

\section{Lesson One: Introduction- Mindful Bodies, Listening, and Breathing \\ Key Points}

- The first session is an opportunity for you to set up the other sessions for the rest of the week.

- Once youth understand your purpose for visiting, they will be better prepared, and the session will go more smoothly.

- When introducing mindfulness, be simple. Too much talking will not be effective, but depending on the interest of the group, explaining a little of how mindfulness can be relevant to their lives can be helpful in obtaining their trust.

1. This document is $4 \mathrm{H} 412$, one of a series of the UF/IFAS Extension Florida 4-H Youth Development Program. Original publication date March 2021. Visit the EDIS website at https://edis.ifas.ufl.edu for the currently supported version of this publication.

2. Heather Janney, county Extension director and 4-H agent, UF/IFAS Extension Columbia County, Lake City, FL 32055.

The Institute of Food and Agricultural Sciences (IFAS) is an Equal Opportunity Institution authorized to provide research, educational information and other services

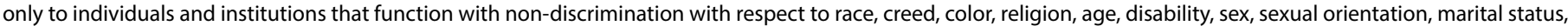

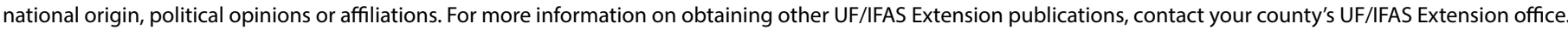
U.S. Department of Agriculture, UF/IFAS Extension Service, University of Florida, IFAS, Florida A \& M University Cooperative Extension Program, and Boards of County Commissioners Cooperating. Nick T. Place, dean for UF/IFAS Extension. 


\section{Facilitator Activity Dialogue}

I will be coming to you each evening this week to teach you something called mindfulness. Has anyone ever heard the word "mindfulness"? Mindfulness is paying attention to what is happening in the present moment. Mindfulness can help us to learn to pay attention to many things and can help us calm down when we are angry, sad, frustrated, or dealing with any difficult emotion. Mindfulness can help us to feel happy and appreciate the positive moments in our days together. It can also help us to focus and do well in a lot of things in our life.

There are a couple of very important things that can help us be mindful. The first thing that will help us during mindfulness is to keep our bodies very still. Can we try that?

Allow 30 seconds for them to get still.

The second thing that happens automatically when we get still...what do you hear?

Yes, it gets very quiet.

Now, we have still bodies and quiet bodies. That's what I call our mindful bodies. Now, let's close our eyes and just lay for one minute.

There are a lot of things that we can be mindful of. Tonight, we are going to practice being mindful of sounds. I brought something to help us with that. Would you like to hear what this sounds like? Okay, but we have to put our mindful bodies back on.

\section{Ring bell.}

Great job everyone. Now, let's try this again, but this time put your mindful ears on. That means you listen very carefully the entire time. So, see if you can pay attention from the very first moment you hear the bell all the way to the end of the sound. Raise your hand when you no longer hear the bell.

\section{Ring bell.}

Since you are so good at this, let's try it one more time with our eyes closed. You are in a safe place. I hope you will feel comfortable to close your eyes. Listen just as you did before and wait for the entire sound to end before raising your hand.

Ring bell.
We can also listen this carefully to any sound. There are lots of sounds around you, and if you listen carefully, you might hear things you don't normally hear. Let's keep our mindful bodies on now and listen to the sounds around us. Okay, let's listen now.

\section{Mindful listening for about one minute}

Raise your hand if you would like to share some of the sounds that you noticed.

Okay, one more thing before we wrap up tonight. What am I doing right now?

\section{Take an obvious inhale and exhale. Let youth identify that} you are breathing.

Yes, I am breathing. We are going to work to be mindful of that. We are always breathing; we don't need to learn how to breathe, but we are learning how to pay attention to our breath. Even though we are always breathing, we usually don't notice it.

Let's try it and see how we feel. Get your mindful bodies back on. Everyone breathe in... and out.

Take a few obvious deep breaths with them. If it seems needed, continue to guide them: "breathe in...breathe out."

Now let's breathe normally like we usually breathe. Keep breathing like that and let your eyes close. Just feel your breath. Now, place your hand on where you feel your breath the most. Do you feel it in your nose, your throat, your chest, or in your belly? Now keep breathing and focus on where you feel your breath the most.

\section{Facilitator Discussion Dialogue}

Our breath right there was our anchor. What is an anchor? What does it do for a boat? Yes, an anchor helps keep the boat where it is. If the boat starts to drift away, the anchor pulls it back in. Well, that is what our breath is doing for our mind. And that's what the bell did for us earlier when it was our anchor. Sometimes when you try to focus on your breath, you might find that your mind starts thinking over lots of different things instead of focusing on your breath. When our mind wanders away from our breath or starts to think about things, we can notice it and bring it right back to our anchor.

Let's focus on our breath for one more minute. I want you to notice the movement in your belly, chest, or nose every time you breathe in and every time you breathe out. I will 
ring the bell after one minute, and that's how we'll finish tonight. Get your mindful bodies on and let your eyes close. Breathe in... and breathe out.

Ring bell after 1 minute.

Good night everyone. Please take a few minutes before I see you next, listening and breathing.

\section{Lesson Two: Body Awareness}

\section{Key Points}

- The word "sensation" might be new or different for some. You can use the word, but make sure they understand it. A sensation is something you can physically feel the touch or pressure of on your skin. This can be confused with the word "feelings." To help youth with understanding that you can physically feel something and then mentally feel something, you should explain the difference between feelings of their physical bodies and feelings mentally or emotionally. More information on this subject can be found in "The Experience of Emotion" (Barrett, Mesquita, Ochsner, \& Gross, 2007).

- Be mindful of the pauses between statements; allow enough time for them to settle into each area, but not so long that they get bored, distracted, etc. Pauses allow time for individuals to reflect upon their physical feelings and to truly know how they feel in that moment.

- Assess their concentration level; if they are concentrated and still, you can stay longer on each spot. If there is lethargy or restlessness, move more quickly through a few spots, then stay longer for one place, then move quickly, etc. Sometimes it might help to stop in between body parts to ask youth what they notice.

- Give examples of sensations they might feel: hard, soft, cold, tingling, movement.

\section{Facilitator Activity Dialogue}

Ring bell. If youth do not automatically get into their mindful body, remind them to put on their mindful bodies and start over.

How is everyone tonight? Who can tell me what mindfulness is? Did anyone notice any different sounds since we talked about mindful listening or breathing?

Tonight, we are going to be mindful of our bodies. Mindfulness of our body can help us in many ways. After we do this today, I'm going to ask you why it might be helpful to be mindful of our bodies.
We are going to take a trip around our body. Put on your mindful body, and again, let your body be very still. Let your eyes close, and without using your hands, pay attention to how your feet feel with your mind. That means feel your feet with your attention, not your hands. What do you feel?

Identify the difference between a thought like "it hurts" and a feeling like "it tingles." One is in the mind; one is in the body. This will be a new concept, but older youth can understand this better.

Now notice your hands. What do you feel?

As I mention each place of your body, I just want you to pay attention to that part and see what you notice. You might notice temperature (warm, cool, or hot), heaviness or lightness, softness or hardness, movement, or something else. Sometimes you might not notice anything in particular.

Now put your attention on your feet again. Notice what they feel like. Maybe you notice what it feels like where they touch your sock or blanket. Notice if you feel softness or hardness, coolness or warmth.

Move your attention to your knees.

Your legs.

Your belly. Take one deep breath in and out.

Your shoulders.

Your arms.

Hands.

Fingertips.

Neck.

Face. Hold your hands just in front of your eyes and let your eyelashes lightly touch your hands.

Head. Can you feel the hair on your head?

Ears.

Ring bell. 


\section{Facilitator Discussion Dialogue}

Where did you notice the most sensations? What sensations did you notice? Did anything surprise you? Did your left side and right side feel the same?

Why would we want to be able to be mindful of our body? We use our bodies for everything: walking, running, sitting, eating, etc. Being mindful of your body helps you take care of your body, and it can be a great way to feel calm and relaxed. Also, if you know anyone in your life who has health problems or trouble falling asleep, you can teach them this body scan. Where can you practice being mindful of your body? At school? On the playground? Before you play sports? Where you live? When you're going to sleep at night?

Let's focus on our breath for one more minute. I want you to think to yourself, moving from one part of your body to the next. I will ring the bell after one minute and that's how we'll finish tonight. Get your mindful bodies on and let your eyes close. Breathing in... and breathing out.

\section{Ring bell.}

Good night everyone. Try to practice scanning your body a few times before I see you next.

\section{Lesson Three: Heartfulness and Emotions}

\section{Key Points}

- Be detailed and transparent about your descriptions of the real-world scenarios.

- Bullying is common with youth in new and/or uncomfortable experiences. It can be thought of as direct behaviors, including teasing, threatening, taunting, and hitting, but it may also be considered as indirect attacks, which cause social isolation through exclusion (Banks, 1997).

- Assess concentration. Stop often and get feedback if the cabin is not staying with you.

- Older kids are conflicted about how to feel when they want to fight back. Some have been conditioned to think fighting back feels good, and that it is not cool to be nice. Acknowledge that rather than judging it.

- Mindfulness of emotions could be the most powerful application of mindfulness.
- For more information on addressing bullying, read How Parents and Agents Can Address Bullying with Youth (Barnett, 2005) at https://edis.ifas.ufl.edu/fy778.

\section{Facilitator Activity Dialogue}

Ring bell. If youth do not automatically get into their mindful bodies, remind them to put on their mindful bodies and start over.

How is everyone tonight? Can someone tell me how they used mindful breathing, listening, or a body scan since I saw you last?

Think of a time that you have felt good because of something nice someone said. Now, think of a time that you have felt bad because of something mean someone said. Will you try an experiment with me tonight to learn why that happens?

Imagine you're hanging out with your friends. Someone in your group gets picked on. Imagine that you laugh at the joke and run off ahead with the friends that made the joke. Notice how you feel, and imagine how your friend who got picked on might feel.

Let's try this again. This time imagine that someone in your group gets picked on. Everyone's laughing. But this time you hang back and tell your friend, "Don't worry, forget about it." Your friend smiles, and you walk together to catch up with the rest of your friends. Notice how you feel this time, and imagine how your friend might feel.

Which feels better? Let them share. The answers might vary. If they do, that's good. Allow it to be a little bit of a conversation about how it's not always obvious or easy to do something kind.

Now imagine you are at camp, or on social media, or at a friend's house, and someone says something very mean to you. Notice how that makes you feel.

\section{Facilitator Discussion Dialogue}

Now imagine that you want to say something mean back to that person. Notice how your body feels and what that's like. You're about to say something or do something, but you stop for just a moment and you take three mindful breaths. Let's do that right now.

Pause and have them take three breaths.

If you still feel angry, take another breath. Now notice how you feel after taking some breaths. 
Let them share. Most will notice that something shifted.

Wow, so for many of you, at first you felt angry, or sad, or frustrated, and then after you used your mindfulness, you felt better, or happier, or calmer. How long did it take for your feeling to change? Just a few breaths. I think that's amazing that you did something for yourself in such a short period of time. Raise your hand if you've ever been angry and it lasted all day. So now you learned a tool to help you when you feel overwhelmed by anger or sadness, or any other strong emotion.

Let's practice this again. Put your mindful bodies on. Breathe in... and breathe out.

Continue this for another minute depending on the concentration and attentiveness of your youth. End by ringing the bell.

As we are about midway through the camp week, everyone is getting tired, and there's a lot going on here at camp. This is something that you'll need to practice in responding to your friends. If you react with each other in a more positive way, you'll get a more positive response, and everyone will have a better time for the rest of our week. Good night everyone. Try to practice mindfulness in your responses to others until we meet again.

\section{Lesson Four: Gratefulness and Gratitude}

\section{Key Points}

- The powerful part of this lesson is in their sharing. Prompt them to share if necessary.

- Self-reflection is an important part of mindfulness because it gives the opportunity to assess how one is feeling in the moment. It can teach us to understand our thoughts, feelings, and actions.

- If this lesson is used on Thursday night of camp, it will be a time to think through the friendships they have made and how they can be continued through letters, through social media, and by attending other $4-\mathrm{H}$ activities.

- If youth still seem restless after this lesson, add in a practice of mindful breathing, listening, and/or body scan.

\section{Facilitator Activity Dialogue}

Ring bell. If youth do not automatically get into their mindful bodies, remind them to put on their mindful bodies and start over.
How is everyone tonight? Can someone tell me how they used mindful breathing, listening, or a body scan since I saw you last?

Can anyone tell me what it means to feel grateful?

Some possible answers: Thankful. Things that make us happy. When we feel happy or thankful about people or things that are in our life.

Okay, let's put our mindful bodies on and close our eyes. Think of three things you are grateful for from this week. Take a deep breath in... and out. And let's think of how those make us feel. Don't focus on only one. Think of one thing and move to the next. Continue breathing in and out.

Ring bell.

Who would like to share one thing that they are most grateful for from this week?

Let them share. Generally, it will be bigger things like canoeing/kayaking, swimming, the dance, etc. Sometimes they may need to hear some examples.

Those were a lot of big, general things that everyone enjoyed. Let's try that again, and this time, think of three smaller things. It could be as small as someone telling you where to go, or sharing a fan, or walking with you somewhere. Now, put your mindful body on and close your eyes. Think of three smaller things. Breathe in... breathe out.

Ring bell.

\section{Facilitator Discussion Dialogue}

Who would like to share one smaller thing that they are grateful for this week?

Let them share.

Close your eyes again, take one deep breath in, and exhale it through your nose. Begin focusing your attention on your heart. Observe any thoughts or images that come into your mind, and then let them go. Continue to think of other different things you are grateful for. It could be people, places, things, moments, or experiences. Continue to ask this question to yourself, allowing any thoughts to arise and then pass, breathing in and out the whole time.

Give them time to think through things. If they seem restless, don't spend too much longer, but go ahead and ring the bell. 
Thank you for taking time to reflect upon our time together this week. Good night.

If you have instructions or activity that needs to be discussed for the morning, please input this here.

\section{References}

Banks, R. 1997. Bullying in schools. https://files.eric.ed.gov/ fulltext/ED407154.pdf

Barnett, R. 2005. How parents and agents can address bullying with youth. EDIS, 2005(15). https://journals.flvc. org/edis/article/view/115222

Barrett, L., Mesquita, B., Ochsner, K., \& Gross, J. 2007. The experience of emotion. Annu Rev Psychol., 58, 373-403. https://doi.org/10.1146/annurev.psych.58.110405.085709

Davis, D., \& Hayes, J. (2011). What are the benefits of mindfulness? A practice review of psychotherapy-related research. Psychotherapy, 48(2), 198-208. https://doi. org/10.1037/a0022062

Mindful Schools. 2014. Mindfulness curriculum: Kindergarten-5 grades. Emeryville, CA.

Naik, P., Harris, V., \& Forthun, L. 2013. Mindfulness: An introduction. EDIS, 2013(8). https://doi.org/10.32473/ edis-fy1381-2013 


\section{Utilizing Mindfulness as an Evening Reflection at Residential Camp}

\section{Evaluation}

This short survey is voluntary. We want to learn more about your experience with Utilizing Mindfulness. Evaluation is not IRB approved currently.

Directions: Please read each statement and circle the number that best represents your experience during these sessions. Make sure to rank each statement's "before" and "after" columns. This survey is ranked on a scale of 1 to 4 as follows:

$1=$ strongly disagree

$2=$ disagree

$3=$ agree

$4=$ strongly agree

\section{Statement}

1.I know what mindfulness is and how it relates to health and wellness.

2. I can identify specific areas of my personal health and wellness that need improvement.

3. I know how to identify stressors to reduce my overall stress level.
Before the lesson

$\begin{array}{llll}1 & 2 & 3 & 4\end{array}$

$\begin{array}{llll}1 & 2 & 3 & 4\end{array}$

$\begin{array}{llll}1 & 2 & 3 & 4\end{array}$
After the lesson

$\begin{array}{llll}1 & 2 & 3 & 4\end{array}$

$\begin{array}{llll}1 & 2 & 3 & 4\end{array}$

$\begin{array}{llll}1 & 2 & 3 & 4\end{array}$

4. What was your favorite thing about the sessions?

5. What is one skill or technique you learned that you would practice on your own? 